\title{
Respiratory Symptoms in Firefighters
}

\author{
Frans E. Greven, MSc, ${ }^{1,2 *}$ Jos M. Rooyackers, MD, PhD, ${ }^{2}$ \\ Huib A.M. Kerstjens, MD, PhD, ${ }^{3}$ and Dick J. Heederik, PhD $^{2,4}$
}

\begin{abstract}
Background The aim of the present study was to determine the prevalence and risk factors associated with respiratory symptoms in common firefighters in the Netherlands. Methods A total of 1,330 firefighters from the municipal fire brigades of three provinces of the Netherlands were included in the study. All subjects were administered a Dutch web-based version of the European Community Respiratory Health Survey questionnaire. Results General respiratory symptoms were associated with the number of fires fought in the last 12 months with odds ratios between 1.2 (95\% CI 1.0-1.4) and 1.4 (95\% CI 1.2-1.7) per 25 fires. A strong association was found between an inhalation incident and present respiratory symptoms with odds ratios between 1.7 (95\% CI 1.1-2.7) and 3.0 (95\% CI 1.94.7). Adjustments for smoking, sex, atopy, and age did not change any of the associations. After stratification, atopics showed elevated odds ratios.

Conclusions It is recommended that firefighters are aware of these elevated healthcare risks associated with exposure to fire smoke and that they increase as much as possible the use of self-contained breathing apparatus. Am. J. Ind. Med. 54:350-355, 2011.

(C) 2011 Wiley-Liss, Inc.
\end{abstract}

KEY WORDS: atopy; firefighter; respiratory symptoms

\section{INTRODUCTION}

Fire fighting is a strenuous activity during which personnel is exposed to risks such as smoke inhalation. Firefighters should carry self-contained breathing apparatus (SCBA) to prevent smoke inhalation. Nevertheless, exposure to toxic hazards is a concern because these devices are often not or not continuously used during firefighting, especially owing to the visual impression of low smoke concentration [Brandt-Rauf

${ }^{1}$ Department of Environmental Health,Municipal Health Services Groningen, Groningen, the Netherlands

${ }^{2}$ Institute for Risk Assessment Sciences, Utrecht University, Utrecht, the Netherlands

${ }^{3}$ Department of Pulmonary Diseases, University Medical Center Groningen, University of Groningen, the Netherlands

${ }^{4}$ Julius Center for Health Sciences and Primary Care, University Medical Center Utrecht, Utrecht, the Netherlands

Contract grant sponsor: The Netherlands Organization for Health Research and Development (ZonMW, The Hague); Contract grant number: 7135.0005 .

The authors declare that they have no financial competing interest.

${ }^{*}$ Correspondence to: Frans Greven, MSc, Department of Environmental Health, Municipal Health Services, Hulpverleningsdienst Groningen, P0 Box 584, 9700 AN, Groningen, the Netherlands. E-mail:f.greven@hvd.groningen.nl

Accepted 15 November 2010

D01 10.1002/ajim.20929. Published online 18 January 2011 in Wiley Online Library (wileyonlinelibrary.com). et al., 1988; Burgess et al., 2001]. Smoke contains substances injurious to airways such as acid gases, aldehydes, and respirable particulate matter [Brandt-Rauf et al., 1988; Hartzell 1996]. Earlier studies have indicated that exposure of firefighters to smoke may result in acute lung function impairment [Musk et al., 1979; Brandt-Rauf et al., 1989; Large et al., 1990], acute increase of airway responsiveness [Chia et al., 1990], and acute increase of respiratory symptoms [Betchley et al., 1997]. Furthermore, studies have suggested that firefighters are at risk of chronic respiratory symptoms and lung function impairment [Mustajbegovic et al., 2001; Miedinger et al., 2007; Ribeiro et al., 2009].

Information about possible respiratory effects of exposure during firefighting has been collected in different countries over several decades. The use of self-contained breathing apparatus has increased over the years and many studies have focused specifically on high risk subcategories such as forest firefighters [Betchley et al., 1997; Slaughter et al., 2004; Swiston et al., 2008], or firefighters in the 9/11 disaster [Prezant et al., 2002; Banauch et al., 2006].

Only few studies with sufficient power have been conducted among common firefighters, and little is known about potential respiratory health risks with modern breathing apparatus. In this study we investigated the respiratory health 
in common firefighters in the Netherlands in relation to exposure to combustion products of fires.

\section{MATERIALS AND METHODS}

\section{Population and Design}

In the present cross-sectional survey, all active firefighters of the municipal fire brigades of three provinces in the Netherlands (Groningen, Friesland, and Drenthe) were invited to fill in a web-based questionnaire. The management of the fire brigades was approached to give information on fires and hazmat incidents in their communities.

The institutional review board for human studies of the University Medical Centre Utrecht (Utrecht, the Netherlands) approved the protocol and informed consent was obtained from all participants.

\section{Questionnaires}

The questionnaire was a web-based version of the European Community Respiratory Health Survey questionnaire translated into Dutch [Kerkhof et al., 1996]. Questions were added to identify the type and number of incidents, the type, the onset, and the duration of symptoms and to determine possible exposure during an incident. General respiratory symptoms during the last 12 months, work-related respiratory symptoms and symptoms indicative of the presence of atopy and bronchial hyper-responsiveness (BHR) were the health outcomes of interest. Atopy, asthma, and BHR were defined on the basis of questionnaire items involving treatment of allergies (asthma, hay fever, eczema, and other allergies) ("Have you ever had asthma"), and BHRlike symptoms (respiratory symptoms in humid air, during acute temperature changes, and when exposed to second hand cigarette smoke, etc.). Exposure was defined on the basis of questionnaire items involving working years, inhalation incidents ("Have you ever inhaled a large amount of smoke") and the number of fires fought during the last 12 months.

\section{Comparison With ELON}

Prevalence of common respiratory symptoms was compared with information from a random sample (2,711 people) of the Dutch population. These symptoms originated from the execution of the Dutch version of the European Community Respiratory Health Survey [European Respiratory Health Study the Netherlands: ELON] [Rijcken et al., 1996].

\section{Statistical Analyses}

The association between firefighter characteristics and reported health symptoms was calculated using a multiple logistic analysis, which also allowed for adjustment for potential confounders. Associations were adjusted for smoking, sex, atopy, and age. Effect modification was examined by analyzing atopic and non-atopic individuals separately and never smoking, formerly smoking, and currently smoking individuals separately. The level of statistical significance was set at $P<0.05$.

\section{RESULTS}

\section{General Information}

In this study all municipal fire brigades $(\mathrm{n}=54)$ in the three northern provinces of the Netherlands were invited. Fire brigades ranged from 1 up to 10 fire stations $(n=142)$ in a municipal fire brigade. Of all fire brigades contacted through surface mail and telephone, 98\% responded; the average worker participation rate per fire brigade was $49 \%$. The management of all fire brigades consisted of professional career firefighters, whereas most of the active firefighters were volunteers (83.9\%). Of 197 professional firefighters (18.8\%) 84 also worked as volunteers (6.9\%).

In the Netherlands, firefighters, professionals, and volunteer, complete the same education, are equally trained, train the same minimal amount of hours monthly and have equal access to SCBA. Furthermore, they undergo mandatory pre-employment as well as periodical (frequency depending on age) medical examinations, but no clear-cut exclusion criteria are being used.

Total number of fires in 2008 in the area was 4,301 (no data available from four fire stations within one fire brigade) and ranged from 5 in a small rural community to 485 in Groningen (185,000 inhabitants). Firefighter characteristics are outlined in Table I. From the 2,814 firefighters, 1,330 (47.3\%) responded, of which the completed questionnaires $(\mathrm{n}=1,249)$ were used for analyses. Most of the firefighters were male $(90.3 \%)$. Firefighters had a mean age of 39.8 years.

\section{Questionnaire Study}

The frequency of symptoms occurring during or immediately following fire fighting in the last 12 months was $31.2 \%$ and ranged from $0.7 \%$ (nosebleeds) to $28.8 \%$ (coughing) (Table II). Eighteen employees (1.8\%) visited a doctor with complaints related to exposure to fire smoke. No differences were found in gender and in smoking behavior among volunteer and other firefighters. Employment as a firefighter was shorter among subject who worked as volunteers $(10.3 \pm 8.0$ years $)$ than professional firefighters 
TABLE I. Descriptive Characteristics of the Firefighters $(n=1,249)$

\begin{tabular}{lccc} 
& Total & Male & Female \\
\hline Sex & $1,249(100)$ & $1,128(90.3)$ & $120(9.6)$ \\
Currentsmoker (no., \%) & $377(30.2)$ & $340(30.1)$ & $37(30.8)$ \\
Ex-smoker (no.,\%) & $332(26.6)$ & $302(26.8)$ & $30(25.0)$ \\
Age,years (mean,SD, range) & $39.8 \pm 8.5(19-60)$ & $40.1 \pm 8.5(20-60)$ & $37.2 \pm 7.4(19-52)$ \\
Working as firefighter,years(mean,SD, range) & $10.8 \pm 8.5(0-39)$ & $11.4 \pm 8.6(0-39)$ & $5.4 \pm 4.8(0-18)$ \\
\hline
\end{tabular}

(13.5 \pm 10.3 years; $P=0.01)$ or those who combined functions $(13.1 \pm 10.0$ years; $P=0.03)$.

The prevalence of respiratory symptoms ranged from $0.5 \%$ (asthma attack during last 12 months) to $19.2 \%$ (BHR-like symptoms). The prevalence of general respiratory symptoms and atopy are shown in Table III.

In an exploratory logistic regression analysis between possible determinants and respiratory symptoms we found associations between the number of fires fought in the last 12 months and some respiratory symptoms with odds ratios between 1.2 (95\% CI 1.0-1.4) and 1.4 (95\% CI 1.2-1.7) per 25 fires (Table IV). The average number of fires fought was 12.2 and the maximum was 302 . One hundred fifty-two firefighters (12.5\%) fought 25 fires or more last year. Exclusion of three subjects fighting more than 200 fires in the last 12 months did not change the associations. Adjustments for smoking, sex, allergy treatment, and age did not change associations. A strong association was found between any inhalation incident and present respiratory symptoms with odds ratios between 1.7 (95\% CI 1.1-2.7) and 3.0 (95\% CI 1.9-4.7). Adjustments for smoking, sex, atopy, and age did not change any of the associations. Being volunteer or professional firefighters was not a determinant of respiratory symptoms.
When we stratified the population into atopic and nonatopic individuals based on the item "Have you ever been treated for an allergic disease" in the questionnaire we found, that odds ratios were slightly elevated for all respiratory symptoms for atopic individuals. The association between the determinant "number of fires fought during the last 12 months" and respiratory symptoms was not significant for non-atopic individuals.

Stratified analyses for smoking behavior did not give any evidence of effect modification for respiratory symptoms.

Comparison with ELON showed a statistically significantly lower prevalence of several respiratory symptoms in firefighters compared with the Dutch general population (Table V). ORs ranged from 0.5 (95\% CI 0.3-0.7) for woken up by shortness of breath to 0.3 (95\% CI $0.2-0.4$ ) for wheeze. There was a statistically significant elevated prevalence of firefighters who had ever had asthma compared to the ELON population an OR of 1.5 (95\% CI 1.1-2.0).

\section{DISCUSSION}

We found a positive association between an increased prevalence of general respiratory symptoms and exposure in

TABLE II. Frequency of Acute Symptoms Following a Fire in the Past 12 Months

\begin{tabular}{|c|c|c|c|c|}
\hline Acute symptoms & Seldom (1-5×)no. $(\%)$ & Frequently $(6-10 \times)$ no. $(\%)$ & Very frequently ( $>10 \times$ ) no. $(\%)$ & Total no.(\%) \\
\hline Wheezing & $30(3.0)$ & $2(0.2)$ & $1(0.1)$ & $33(3.3)$ \\
\hline Coughing & $271(27.4)$ & $12(1.2)$ & $2(0.2)$ & $285(28.8)$ \\
\hline Shortness of breath & $74(7.5)$ & $4(0.4)$ & $2(0.2)$ & $80(8.1)$ \\
\hline Irritation of the lungs & $77(7.8)$ & $2(0.2)$ & $2(0.2)$ & $81(8.2)$ \\
\hline Itchy eyes & $151(15.3)$ & $5(0.5)$ & 0 & $156(15.8)$ \\
\hline Itchynose & $109(11.0)$ & $10(1.0)$ & $1(0.1)$ & $120(12.2)$ \\
\hline Sore throat & $98(9.9)$ & $5(0.5)$ & 0 & $103(10.4)$ \\
\hline Headache & $126(12.8)$ & $10(1.0)$ & $1(0.1)$ & $137(13.9)$ \\
\hline Nosebleeds & $4(0.4)$ & $3(0.3)$ & 0 & $7(0.7)$ \\
\hline Dizziness & $33(3.3)$ & $2(0.2)$ & 0 & $35(3.5)$ \\
\hline Nausea & $13(1.3)$ & $1(0.1)$ & 0 & $14(1.4)$ \\
\hline Chest pain & $18(1.8)$ & $1(0.1)$ & 0 & $19(1.9)$ \\
\hline Feeling of weakness & $25(2.5)$ & $1(0.1)$ & 0 & $26(2.6)$ \\
\hline
\end{tabular}


TABLE III. General Respiratory Symptoms

\begin{tabular}{lc} 
General respiratory symptoms & Number (\%) \\
\hline Wheeze during last12 months & $95(7.7)$ \\
$\quad$ Yes, with shortness of breath & $59(4.8)$ \\
Woken up by shortness of breath during last12 months & $31(2.5)$ \\
Cough at wake up during winter & $64(5.2)$ \\
Cough at day/night time during winter & $85(6.9)$ \\
Phlegm at wake up during winter & $56(4.5)$ \\
Phlegm at day/night time during winter & $41(3.3)$ \\
Dyspnea when walking on a flat surface with people of the same age & $14(1.1)$ \\
Haveyou ever had asthma? & $93(7.5)$ \\
Was it doctor diagnosed & $89(7.2)$ \\
Asthmaattackduring last12 months & $6(0.5)$ \\
Asthma medication at moment & $30(2.4)$ \\
Bronchial hyperresponsiveness-like symptoms & $235(19.2)$ \\
Allergy treatment & $245(19.8)$ \\
\hline
\end{tabular}

firefighters. Furthermore, a positive association was found between general respiratory symptoms and the number of fires fought in the last 12 months. Firefighters showed a higher prevalence of asthma than a Dutch general population sample. On the other hand, firefighters showed a lower prevalence of several respiratory symptoms than this population sample. It was found that the effect of exposure to fire smoke was higher in atopics.

The crude associations were adjusted for gender, age, smoking, and atopy, which had no major effect.

In this study, the exposure was estimated using a questionnaire. The questionnaire items working years, inhalation incidents, and number of fires fought in the last 12 months were used as proxies for exposure. Other studies have shown an association between exposure and reduction in pulmonary function [Musk et al., 1979; Douglas et al., 1985; Mustajbegovic et al., 2001]. However, since most of these associations were found in a time when SCBA was not yet commonly used, the more remarkable it is that respiratory symptoms are associated with the number of fires fought in the last 12 months in a time when SCBA's are widely used. Others have suggested that, although the availability and effectiveness of protective devices such as SCBA's has increased, SCBA is insufficiently used by firefighters due to its weight and inconvenience, especially when smoke is not visible and during phases of overhaul or work in the second line (drivers, pump manipulators), when important exposure to combustion products may persist [Burgess et al. 2001; Miedinger et al., 2007]. Our results that respiratory symptoms are associated with the number of fires fought, suggests that the use of SCBA's should still be increased. Additionally, the development of a lighter SCBA would facilitate the use of it, and should therefore be encouraged. In our study, respiratory symptoms were strongly associated with an inhalation incident with a large amount of smoke considerable smoke during which a large amount of smoke may have been inhaled. These associations are consistent with studies among residents, firefighters, and other workers involved in the WTC disaster [Banauch et al., 2003; Herbstman et al., 2005; Reibman et al., 2005]. Working years was not associated with symptoms which is also consistent with earlier studies [Sparrow et al., 1982; Sherman et al., 1989]. By contrast, Mustajbegovic et al. [2001] demonstrated a positive relationship of respiratory symptoms with working years. Austin et al. [2001] suggested that reliance on years of employment as a surrogate for exposure might lead to misclassification of exposure and therefore underestimation of the risk of disease. The observation that working years is a

TABLE IV. Association Between General Respiratory Symptoms and Exposure

Exposure estimates

\begin{tabular}{|c|c|c|c|c|}
\hline \multirow[b]{2}{*}{ General respiratory symptoms } & \\
\hline & $\begin{array}{c}\text { Number of fires, } \\
\text { crude odds ratio } \\
\text { (95\% CI) }\end{array}$ & $\begin{array}{l}\text { Number of fires, } \\
\text { adjusted odds ratio } \\
(95 \% \mathrm{CI})\end{array}$ & $\begin{array}{l}\text { Inhalation incident, } \\
\text { crude odds ratio } \\
\text { (95\% CI) }\end{array}$ & $\begin{array}{l}\text { Inhalation incident, } \\
\text { adjusted odds ratio } \\
\text { (95\% CI) }\end{array}$ \\
\hline Wheeze during last 12 months & $1.2(<1.0-1.4)$ & $1.1(0.9-1.3)^{\mathrm{a}}$ & $2.3(1.5-3.5)$ & $2.3(1.5-3.6)^{\mathrm{a}}$ \\
\hline Woken up by shortness of breath during last 12 months & $1.0(0.7-1.5)$ & $1.0(0.6-1.5)^{\mathrm{a}}$ & $1.2(0.6-2.6)$ & $1.2(0.5-2.5)^{\mathrm{a}}$ \\
\hline Cough at wake up during winter & $1.1(0.9-1.4)$ & $1.1(0.9-1.4)^{\mathrm{a}}$ & $2.3(1.4-3.8)$ & $2.3(1.4-3.9)^{\mathrm{a}}$ \\
\hline Cough at day/night time during winter & $1.3(1.1-1.5)$ & $1.3(1.1-1.5)^{\mathrm{a}}$ & $3.0(1.9-4.7)$ & $3.0(1.9-4.7)^{\mathrm{a}}$ \\
\hline Phlegm at wake up during winter & $1.4(1.2-1.7)$ & $1.4(1.1-1.7)^{\mathrm{a}}$ & $2.8(1.6-4.8)$ & $2.8(1.6-4.8)^{\mathrm{a}}$ \\
\hline Phlegm at day/night time during winter & $1.4(1.1-1.6)$ & $1.3(1.1-1.6)^{\mathrm{a}}$ & $1.8(<1.0-3.4)$ & $1.8(<1.0-3.4)^{\mathrm{a}}$ \\
\hline Have you ever had asthma? & $1.3(1.1-1.5)$ & $1.2(1.0-1.5)^{\mathrm{a}}$ & $1.7(1.1-2.7)$ & $1.8(1.1-2.8)^{\mathrm{a}}$ \\
\hline Bronchial hyperresponsiveness-like symptoms & $1.1(<1.0-1.3)$ & $1.1(<1.0-1.3)^{\mathrm{a}}$ & $2.4(1.8-3.2)$ & $2.5(1.8-3.4)^{\mathrm{a}}$ \\
\hline Allergy treatment & $1.2(1.0-1.4)$ & $1.2(1.0-1.4)^{b}$ & $1.1(0.8-1.5)$ & $1.1(0.8-1.5)^{\mathrm{b}}$ \\
\hline
\end{tabular}

${ }^{\mathrm{a}} 0 \mathrm{dds}$ ratio adjusted for age, gender, smoking, and atopy.

${ }^{\mathrm{b}}$ Odds ratio adjusted for age, gender, and smoking. 
TABLE V. Comparison of General Respiratory Symptoms in Firefighters and General Respiratory Symptoms in the General Dutch Population, ELON ( $\mathrm{n}=2,711)$, Adjusted for Age, Smoking, and Gender

\begin{tabular}{lc} 
General respiratory symptoms & (95\% Cl) \\
\hline Wheeze during last 12 months & $0.3(0.2-0.4)$ \\
Woken up by shortness of breath during last 12 months & $0.5(0.3-0.7)$ \\
Coughat wake up during winter & $0.4(0.3-0.6)$ \\
Coughat day/night time during winter & $0.4(0.3-0.5)$ \\
Phlegmat wake up during winter & $0.4(0.3-0.6)$ \\
Phlegm at day/night time during winter & $0.3(0.2-0.5)$ \\
Haveyou ever had asthma? & $1.5(1.1-2.0)$ \\
Dyspnea when walking on a flat surface & $0.3(0.3-0.5)$ \\
\hline
\end{tabular}

poor proxy for exposure is supported by our finding that the median number of fires fought in the last working year was 6 with a minimum of 0 fires $(13.9 \%)$ and a maximum of more than $100(0.8 \%)$.

It is of interest that the risk of respiratory symptoms in atopics was elevated compared to non-atopics. This is a strong indication for effect modification by atopy that should be further investigated in a study with objective measures.

Brooks et al. [1998] suggested before that atopy may be a risk factor for (not-so-sudden onset) irritant-induced asthma. In a recently performed study it was found that the prevalence of atopy based upon skin prick test was higher among urban firefighters compared with a Swiss population sample [Miedinger et al., 2007]. Associations of atopy based on $\mathrm{IgE}$ with exposure of non-allergenic compounds have been found in earlier studies [Preller et al., 1996]. A possible mechanism underlying these associations could be a disruption of the lung epithelial barrier facilitating the penetration of allergens in the lung [Bernard et al., 2003]. As the prevalence of allergic rhinitis has risen in the world over the last decades [Bousquet et al., 2008], it is of importance to evaluate the role of atopy in the prevalence of respiratory symptoms in firefighters.

The presence of general respiratory symptoms in firefighters might partly be explained by temporary acute respiratory symptoms following exposure to fire smoke. However, we cannot rule out that some exposed firefighters might suffer from RADS (reactive airways dysfunction syndrome) or IIA (irritant-induced asthma). The current study showed a lower prevalence of several respiratory symptoms in firefighters compared to a Dutch general population sample. In the Netherlands firefighters undergo mandatory pre-employment as well as periodical (frequency depending on age) medical examinations, including lung function testing, but no clearcut exclusion criteria are being used. Depending on their age, they will be re-examined as frequently as every 2 or 4 years. This selection mechanism combined with the healthy worker effect might explain the differences in respiratory symptom prevalence between the two populations. However, the observation of a higher prevalence of asthma among firefighters is remarkable and cannot be explained this way. In this light, it should be emphasized that the finding that exposure is associated with respiratory symptoms was demonstrated in a relatively healthy population. The higher prevalence of asthma in this study therefore is unexpected. We do not at current have an explanation. Information bias is an unlikely explanation, because in a subset of 402 firefighters, asthma and wheezing in the last 12 months were associated with BHR (OR [95\% CI], 5.5 [2.6-11.6], respectively, OR [95\% CI], 2.7 [1.35.6]). The apparent increase in asthma occurrence seems real and we can thus not rule out an increased risk for developing irritant-induced asthma in firefighters.

Since only $49 \%$ of the firefighters completed the questionnaire, selection bias might have occurred. However, reported symptom prevalence in fire brigades with a high response $(>60 \%)$ were comparable with fire brigades with a lower response $(<40 \%)$. Responder bias would probably be a more important limiting factor. A good contact with the study population was difficult, because they could only to be approached with an invitation letter with general encouragement by the management.

As in other questionnaire studies, recall bias may have occurred. Possibly low-level smoke concentration is not judged as a health risk. For instance, firefighters who have experienced a substantial inhalation incident will probably not refer to minor incidents. During the most recent fire $55.4 \%$ of the firefighters was exposed to visible smoke and/or noticed inhalation of smoke. Furthermore, an inhalation incident was associated with the number of fires (OR [95\% CI], 1.2 [1.0-1.4] per 25 fires), which argues against a major influence of recall bias.

In conclusion, we have found clear associations between number of fires and inhalation incidents with respiratory symptoms at present. Despite a potential healthy worker effect and the possible influence of pre-employment medical examinations, exposed individuals reported respiratory symptoms more often. It is recommended that firefighters are aware of these elevated healthcare risks associated with exposure to fire smoke and that they increase as much as possible the use of SCBA.

\section{ACKNOWLEDGMENTS}

This study was supported by grant for project number 7135.0005 from the Netherlands Organisation for Health Research and Development (ZonMW, The Hague). The authors wish to thank the personnel of the fire brigades of the Provinces Groningen, Friesland, and Drenthe for their cooperation in this study, and Eef van Otterloo (Institute for Risk Assessment Sciences, Utrecht University, Utrecht, the Netherlands) for designing the web-based questionnaire. 


\section{REFERENCES}

Austin CC, Dussault G, Ecobichon DJ. 2001. Municipal firefighter exposure groups, time spent at fires and use of self-contained-breathing-apparatus. Am J Ind Med 40:683-692.

Banauch GI, Alleyne D, Sanchez R, Olender K, Cohen HW, Weiden M, Kelly KJ, Prezant DJ. 2003. Persistent hyperreactivity and reactive airway dysfunction in firefighters at the World Trade Center. Am J Respir Crit Care Med 168:54-62.

Banauch GI, Hall C, Weiden M, Cohen HW, Aldrich TK, Christodoulou V, Arcentales N, Kelly KJ, Prezant DJ. 2006. Pulmonary function after exposure to the World Trade Center collapse in the New York City Fire Department. Am J Respir Crit Care Med 174:312-319.

Bernard A, Carbonnelle S, Michel O, Higuet S, De Burbure C, Buchet JP, Hermans C, Dumont X, Doyle I. 2003. Lung hyperpermeability and asthma prevalence in schoolchildren: Unexpected associations with the attendance at indoor chlorinated swimming pools. Occup Environ Med 60:385-394.

Betchley C, Koenig JQ, van Belle G, Checkoway H, Reinhardt T. 1997. Pulmonary function and respiratory symptoms in forest firefighters. Am J Ind Med 31:503-509.

Bousquet J, Khaltaev N, Cruz AA, Denburg J, Fokkens WJ, Togias A, Zuberbier T, Baena-Cagnani CE, Canonica GW, van Weel C, Agache I, it-Khaled N, Bachert C, Blaiss MS, Bonini S, Boulet LP, Bousquet PJ, Camargos P, Carlsen KH, Chen Y, Custovic A, Dahl R, Demoly P, Douagui H, Durham SR, van Wijk RG, Kalayci O, Kaliner MA, Kim YY, Kowalski ML, Kuna P, Le LT, Lemiere C, Li J, Lockey RF, MavaleManuel S, Meltzer EO, Mohammad Y, Mullol J, Naclerio R, O’Hehir RE, Ohta K, Ouedraogo S, Palkonen S, Papadopoulos N, Passalacqua G, Pawankar R, Popov TA, Rabe KF, Rosado-Pinto J, Scadding GK, Simons FE, Toskala E, Valovirta E, Van Cauwenberge P, Wang DY, Wickman M, Yawn BP, Yorgancioglu A, Yusuf OM, Zar H, nnesiMaesano I, Bateman ED, Ben KA, Boakye DA, Bouchard J, Burney P, Busse WW, Chan-Yeung M, Chavannes NH, Chuchalin A, Dolen WK, Emuzyte R, Grouse L, Humbert M, Jackson C, Johnston SL, Keith PK, Kemp JP, Klossek JM, Larenas-Linnemann D, Lipworth B, Malo JL, Marshall GD, Naspitz C, Nekam K, Niggemann B, NizankowskaMogilnicka E, Okamoto Y, Orru MP, Potter P, Price D, Stoloff SW, Vandenplas O, Viegi G, Williams D. 2008. Allergic Rhinitis and its Impact on Asthma (ARIA) 2008 update (in collaboration with the World Health Organization, GA(2)LEN and AllerGen). Allergy 63 (Suppl 86): $8-160$.

Brandt-Rauf PW, Fallon LF, , Tarantini T, Idema C, Andrews L. 1988. Health hazards of fire fighters: Exposure assessment. Br J Ind Med 45: 606-612.

Brandt-Rauf PW, Cosman B, Fallon LF, , Tarantini T, Idema C. 1989. Health hazards of firefighters: Acute pulmonary effects after toxic exposures. Br J Ind Med 46:209-211.

Brooks SM, Hammad Y, Richards I, Giovinco-Barbas J, Jenkins K. 1998. The spectrum of irritant-induced asthma: Sudden and not-sosudden onset and the role of allergy. Chest 113:42-49.

Burgess JL, Nanson CJ, Bolstad-Johnson DM, Gerkin R, Hysong TA, Lantz RC, Sherrill DL, Crutchfield CD, Quan SF, Bernard AM, Witten ML. 2001. Adverse respiratory effects following overhaul in firefighters. J Occup Environ Med 43:467-473.

Chia KS, Jeyaratnam J, Chan TB, Lim TK. 1990. Airway responsiveness of firefighters after smoke exposure. Br J Ind Med 47:524527.
Douglas DB, Douglas RB, Oakes D, Scott G. 1985. Pulmonary function of London firemen. Br J Ind Med 42:55-58.

Hartzell GE. 1996. Overview of combustion toxicology. Toxicology 115:7-23.

Herbstman JB, Frank R, Schwab M, Williams DL, Samet JM, Breysse PN, Geyh AS. 2005. Respiratory effects of inhalation exposure among workers during the clean-up effort at the World Trade Center disaster site. Environ Res 99:85-92.

Kerkhof M, Droste JH, de Monchy JG, Schouten JP, Rijcken B. 1996. Distribution of total serum IgE and specific IgE to common aeroallergens by sex and age, and their relationship to each other in a random sample of the Dutch general population aged 20-70 years. Dutch ECRHS Group, European Community Respiratory Health Study. Allergy 51:770-776.

Large AA, Owens GR, Hoffman LA. 1990. The short-term effects of smoke exposure on the pulmonary function of firefighters. Chest 97:806-809.

Miedinger D, Chhajed PN, Stolz D, Gysin C, Wanzenried AB, Schindler C, Surber C, Bucher HC, Tamm M, Leuppi JD. 2007. Respiratory symptoms, atopy and bronchial hyperreactivity in professional firefighters. Eur Respir J 30:538-544.

Musk AW, Smith TJ, Peters JM, McLaughlin E. 1979. Pulmonary function in firefighters: Acute changes in ventilatory capacity and their correlates. Br J Ind Med 36:29-34.

Mustajbegovic J, Zuskin E, Schachter EN, Kern J, Vrcic-Keglevic M, Heimer S, Vitale K, Nada T. 2001. Respiratory function in active firefighters. Am J Ind Med 40:55-62.

Preller L, Doekes G, Heederik D, Vermeulen R, Vogelzang PF, Boleij JS 1996. Disinfectant use as a risk factor for atopic sensitization and symptoms consistent with asthma: An epidemiological study. Eur Respir J 9:1407-1413.

Prezant DJ, Weiden M, Banauch GI, McGuinness G, Rom WN, Aldrich TK, Kelly KJ. 2002. Cough and bronchial responsiveness in firefighters at the World Trade Center site. N Engl J Med 347:806-815.

Reibman J, Lin S, Hwang SA, Gulati M, Bowers JA, Rogers L, Berger KI, Hoerning A, Gomez M, Fitzgerald EF. 2005. The World Trade Center residents' respiratory health study: New-onset respiratory symptoms and pulmonary function. Environ Health Perspect 113:406-411.

Ribeiro M, de Paula SU, Bussacos MA, Terra-Filho M. 2009. Prevalence and risk of asthma symptoms among firefighters in Sao Paulo, Brazil: A population-based study. Am J Ind Med 52:261-269.

Rijcken B, Kerkhof M, de Graaf M. 1996. Europees Luchtwegonderzoek Nederland [European Respiratory Health Study the Netherlands]. Rijksuniversiteit Groningen, Groningen, the Netherlands.

Sherman CB, Barnhart S, Miller MF, Segal MR, Aitken M, Schoene R, Daniell W, Rosenstock L. 1989. Firefighting acutely increases airway responsiveness. Am Rev Respir Dis 140:185-190.

Slaughter JC, Koenig JQ, Reinhardt TE. 2004. Association between lung function and exposure to smoke among firefighters at prescribed burns. J Occup Environ Hyg 1:45-49.

Sparrow D, Bosse R, Rosner B, Weiss ST. 1982. The effect of occupational exposure on pulmonary function: A longitudinal evaluation of fire fighters and nonfire fighters. Am Rev Respir Dis 125:319-322.

Swiston JR, Davidson W, Attridge S, Li GT, Brauer M, van Eeden SF 2008. Wood smoke exposure induces a pulmonary and systemic inflammatory response in firefighters. Eur Respir J 32:129-138. 